\title{
An Application of Online Branding Design with Customisation, Culture and Communities Strategy : A case studies on six online store providers
}

\author{
1) Mahjudin \\ 2) Achmad Daengs GS \\ 3) Retno Susanti \\ Universitas 45 Surabaya Indonesia \\ 1) mahjudin@gmail.com \\ 2) bumigora80@gmail.com \\ 3) retsan45@gmail.com
}

\begin{abstract}
In order to boost the value of an e-brand, we need to consider appropriate design strategies using the interactive capabilities of the Internet in an online marketplace. The purpose of this study is to investigate diverse experiential and emotional marketing strategies for online brands and to suggest various methods to create powerful emotional contents of e-brand's sites. In this paper, we examine the effects of emotional branding on the current marketplace and explore the characteristics of e-brands. The research processes in this paper are to: (1) investigate diverse theories related to emotional and experimental marketing through literature review; (2) develop a "Customisation, Culture and Communities Strategy" model as an emotional e-branding method; (3) analyze well-established e-brands websites with this Customisation, Culture and Communities Strategy; and (4) identify the effects of emotional e-brand contents and the designer's role of visualizing the emotional contents. This study provides a new perspective on online marketing and designing a virtual environment to realize the desired customer experiences. Key words: E-brand Design Strategy, E-branding, Emotional branding, Experiential Marketing.
\end{abstract}

Keyword : Brand extension, Online consumer perception, Online brandig

\section{Introduction}

\subsection{Background and Purposes}

In today's business environment, many companies havean online presence like a corporate web site or a social networking site. The online marketplace not only provides an extensive information opportunity but also hasamazing volumes of spending and cost effective benefits. Instead of looking at the internet as another medium for information and transactions, firms must take into account the internet for the brand building process. According to Salmeron and Hurtado [3], the most important three factors that are associated with the reason to establish e-commerce are: increase of revenue, facilitation of the purchases from consumers and amplification of the brand 
recognition. The internet has changed due to the connection of consumers with brands; it is transforming marketing and outdating traditional branding strategies. That means, traditional branding strategies must be redesigned in accordance with the changing relationship of customer and brand. Additionally, the advent of the internet has madOnline Branding more complex and a dynamic challenge. In this context, Online Branding strategies have increasingly become an important topic.

The recent growth of online shops is a fact that can't be ignored within the framework of e-commerce. According to Harris and Dennis as cited by Dennis et al. [8], the business of online retailing can be defined as the sale of goods and services via internet or other electronic channels, for personal or household use by consumers. There are a number of advantages for online retailers. Firstly, the selling location is not important which is they can ship to anywhere in the country and even overseas. Furthermore, the size of the market is unimportant; small online retailers can compete on equal terms with large ones [8]. Besides many other advantages of online retailing, retailers have several types of online practices. Each of the brick and mortar brands or pure e-tailer brands are based on a business model which significantly improves the value equation through greater consumer interactivity, enhanced consumer experiences, tailoring and rapid response [10]. Moreover, in an online shopping environment where physical interaction is reduced, Online Branding may be increasingly important. „Pure e-tailers need an attractive offering, a viable business model and a brand management team for competitive advantages. So in the context of pure e-tailers, Online Branding strategies can be assumed to play an important role in this business model.

The marketplace has been dramatically transformed into "peopledriven economy," which puts customers in control, accompanying shifts of economic bases from production to consumption, from the sphere of rationality to the realm of desire, and from the objective to the subjective [1]. As the Internet in particular has proliferated concurrently with this trend, various e-brands of Internet ventures or Internet start-ups have rapidly been built. And also most established brick and mortar companies have brought their brands from the physical world to the Internet [2], [3]. The web site's accessibility, flexibility, and interaction endow an e-brand with the unprecedented potential to provide new transaction experiences, which include constantly innovative and fashionable visuals and interactive communication methods. In the online setting, however, customers are usually unable to be engaged in sensory experiences; speaking directly with a salesperson, holding a product, and communicating with lots of visual images in a shop. Owing mainly to the absence of human interaction and sensory elements, an e-brand has a need to create the "Emotional Zones," providing more sensorial experiences than a brick-and-mortar company's brand in the real world. The purposes of this study, therefore, are to develop an e-branding strategy based on the customer's sensorial experiences, to analyze well-established e-brands with the e- 
branding strategy, and finally to identify the effects of designing emotional e-brand's contents by enhancing interactive features of customization, communication, and culture.

\section{Literature review}

\subsection{Online Branding}

Online Branding Kotler [2] defines the brand term as, "a name, term, sign, symbol, or design, or combination of them which is intended to identify the goods and services of one seller or group of sellers and to differentiate them from those of competitors". Consumers can reduce complexity and information processing time with the help of branding. Moreover, branding enhances the trust between customers and companies [3]. But a manager's mentality needs to improve to compete successfully with brands in the digital age [2], because there are a lot of online facilities which can affect brands in a variety of ways [5].Several authors have suggested that Online Branding needs to build on and integrate with branding through other channels [6]. First of all, it is essential to understand what we mean by an online brand. According to Rowley [6], an online brand is "a brand that has an online presence". Dayalet al. states that, "the brand is the experience and the experience is the brand," on the World Wide Web. It can be assumed that effective Online Branding may build up customer loyalty, provoke sale volume and cause higher revenue. Besides many other advantages of Online Branding, different business types have different goals for their online channels and different online Branding strategies. The success of online Branding depends on Online Branding strategies and online goals. Online Branding process builds the value of the brand to the business, or its brand equity[6]. Brands need to make their brand values very clear to be successful online for long term [5].

\subsection{Emotional Branding}

In the current overcrowded marketplace, where a wide variety of products and services offer the same features, a customer's buying decision among competitive brands is affected not only by the features and benefits of products, but also by believable and fascinating promises that are deeply rooted in human emotions experienced in the right brain [4], [5]. In order to strengthen brand's competitiveness, companies have to scrupulously investigate customer's sensorial needs and desires to create a deeper and closer partnership with the customer through an emotional dialogue, setting their product apart from other brands. Therefore, effective online branding ultimately means managing people's emotions and creating positive receptivity to brands [1], [5]. From this emotional perspective, Marc Gobé [7] emphasized the importance of considering emotion and suggested "emotional branding" as a methodology for connecting products to people in an emotionally profound way [1]. Because all people respond emotionally to their life experiences and naturally project emotional values onto the objects around them, this emotional approach can help companies build feasible brands for bringing pleasurable, life-enhancing solutions to customer's daily lives. Moreover, powerful 
emotional branding comes from profound relationships and intimate personal dialogues with customers, and this branding brings long-lasting loyalty in the end. Especially, these profound relationships can be created based on emotional connectivity with customers, and the emotional dialogues with customers on more refined and complex need for diversity provide emotional satisfaction transcending material pleasure. Therefore, we analyze that the profound relationship and emotional dialogue can be created, recreated, and sustained through Gobé's emotional branding concept based on four essential pillars: relationship, sensorial experiences, imagination, and vision. These pillars provide a blueprint of identifying a successful emotional branding strategy [1].

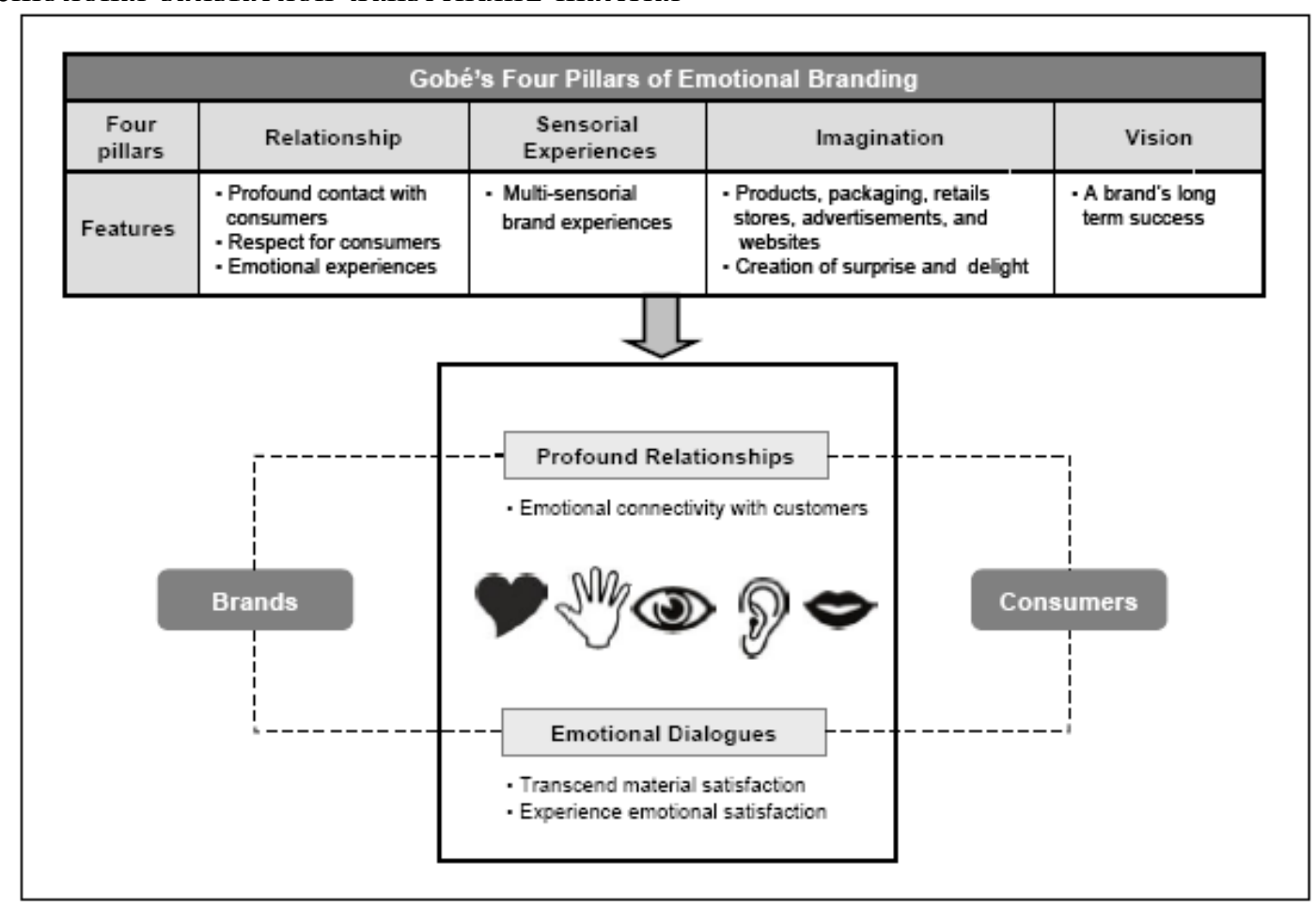

Fig. 2 A Blueprint of Constructing Emotional Branding through Gobé's Four Pillars of Emotional Branding

Firstly, relationship refers to connecting with customers, showing respect for them, and giving them the emotional experience they really want. Secondly, the sensorial experience, which is composed of multi-sensorial brand experiences, is a key to achieving memorable brand contact that will establish brand preference and create loyalty. Thirdly, emotional branding can be realized through imaginative approaches to the design of products, retails stores, advertisements, websites, and so on [4]. And finally, all these experiences create a strong brand vision, the ultimate factor of a brand's long-term success, through continually surprising and delighting consumers [1]. The above Fig. 2 shows how a brand can create profound relationship and emotional dialogues with consumers through Gobé's Four Pillars of Emotional Branding. 


\subsection{Emotional Branding Approach to Online Branding}

E-commerce empowers customers to buy with the ease of shopping $24 / 7$, enabling them to save time since all locations are just a mouse-click away. Besides this convenience of shopping, customers tend to actively seek information by visiting websites and expect more choices and greater value [1]. In a more customer-driven online atmosphere, companies have to understand the varied and relevant needs of web users and deliver the right experience to them, which establishes brand awareness, brand association, brand loyalty, and other brand assets [6]. However, in a new virtual world, getting higher brand equity is difficult because customers are virtually shopping with the lack of personal and sensitive stimuli compared to the physical world; therefore, we need to apply emotional branding strategies to the e-brand creation based on online shopping experiences. It is assumed that emotional branding strategies provide good e-branding methods of attracting customers, building emotional relationships, and creating customer loyalty.

\subsubsection{Online Branding}

Compared to many of the brands built up over many years based on brickand-mortar industries, there is a new way of branding in click-and-click companies, called e-commerce industries. An e-brand is designed in cyberspace through the ecommerce marketing; however, e-brands are still not fully understood because of the complexities that typify the new digital marketplaces, electronic consumer behavior, and the attributes that comprise a successful e-brand [7]. In terms of an e-brand's complexities, to transform visitors into customers, the Internet firm has to develop a successful Internet retail environment, which provides visitors with numerous emotional brand experiences and enjoyable memories by using the Internet's extraordinary multimedia capabilities. In order to develop strong e-brands, the Internet companies have to concentrate on an e-brand's features such as connectivity, entertainment, memorability, and so on.

\subsubsection{Emotional Online Branding with Customisation, Culture and Communities Strategy}

Combined with emotional branding strategies, the online branding (ebrand)Online brand has a powerful potential for building an essential connection with the customer because emotional branding supports customer's engagement in both active and interactive experiences by delivering an increasingly accessible and rich array of sensory experiences through the Internet's multimedia capabilities [7]. Namely, Online brand with a plethora of attractive contents give opportunities for emotional dialogue and provide sensorial experiences to customers. Through sensorial experiences and emotional dialogues, ebrands promote a profound relationship, and then establish their long-term competitiveness, not just differentiation among other Online brand. Therefore, in order to develop an e-branding process with emotional branding strategies, we use the Gobé's four pillars of emotional branding process shown in Fig. 2, and adapt it as a 
blueprint to explain essential characteristics of "emotional e-branding." With considering the characteristics of the new digital marketplace and electronic consumer behavior, we select four pillars as key elements of creating emotional e-branding: emotional communications, customized experiences, multimedia capabilities, and communities.

Firstly, in cyberspace lacking of face-to-face negotiations, Online brand make consumers visit their websites by endeavoring to effectively provide highquality information, and then construct more intimate relationships with consumers through emotional communication. Secondly, customized services and memorable experiences play a role of sensorial experiences and sensitive stimuli by satisfying electronic consumers' expectation of more choices and greater value. Thirdly, Internet's multimedia capacities as imaginative tools enable consumer's varied and relevant emotional needs to be visualized. Therefore, the potential for using diverse multimedia attributes allows companies to provide exhilarating services unique to the online market. Finally, Online brand view communities as a way to build the brand's vision and maintain customer loyalty by fostering an active community atmosphere and constantly gaining closer connection with customers. The following Fig. 3 shows the relationship between four pillars of Gobé's emotional branding and those of emotional e-branding.

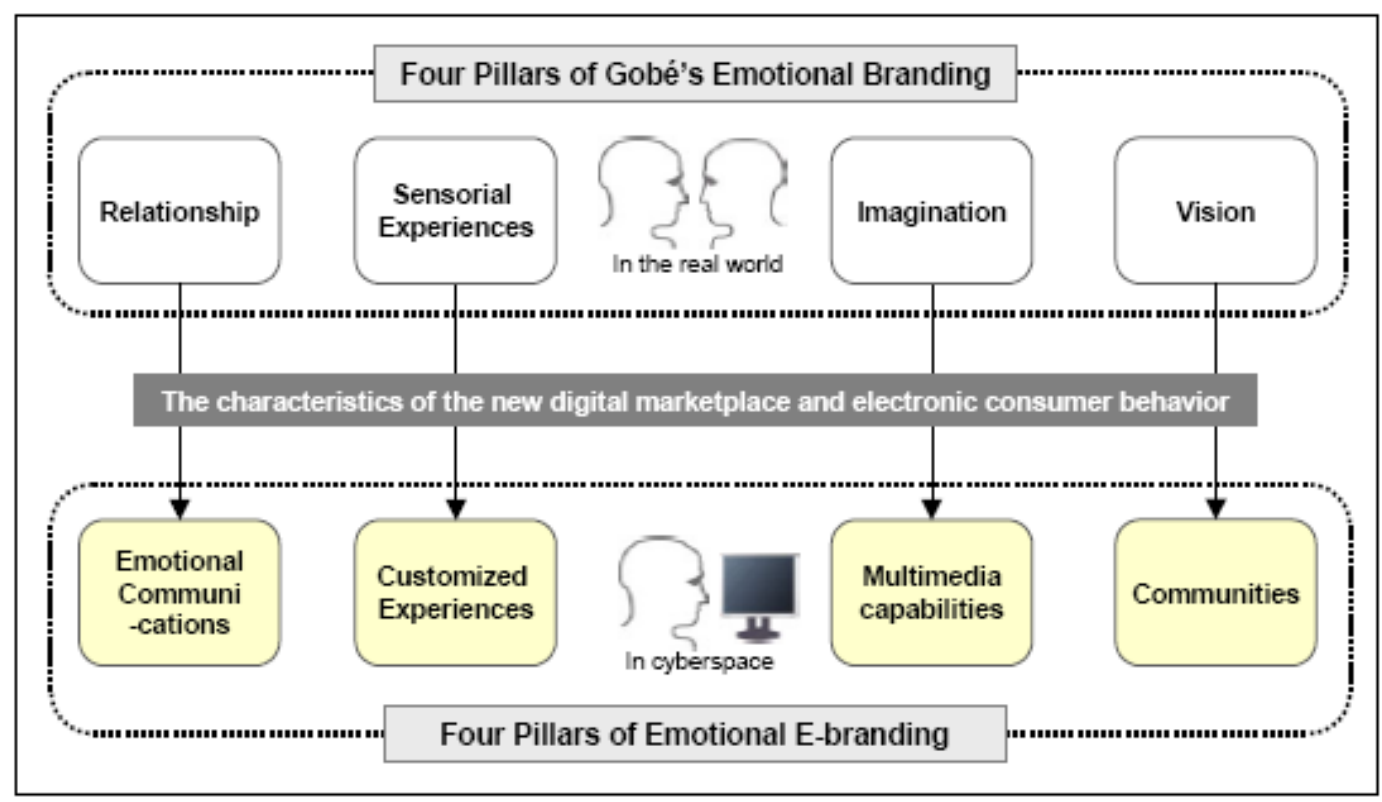

Fig. 3 Four Pillar's of Gobé's Emotional Branding and Those of Emotional E-branding

Furthermore, as an effective method for conducting four pillars of emotional ebranding, we develop a "Customisation, Culture and Communities Strategy," including Customization, Communication, and Culture, based on the features of ebrand's four pillars. The Customisation, Culture and Communities Strategy provides emotional experiences through the services of customization and consideration, and 
these experiences can be emotionally visualized by using multi-sensorial and multi-dimensional media attributes such as visual, audible, kinetic, and tactile properties. Especially, in an onlinemarketplace, an innovative service globally creates new digital culture, which brings a whole new way of life and enhancing a customer's life. The below Fig. 4 explains a process of developing three elements of Customisation, Culture and Communities Strategy from four pillars of emotional online branding and identify each characteristic of three elements. Customized experiences, through Internet's multimedia capabilities, are embodied on websites and delivered to customers as customization services. Among four pillars, meanwhile, emotional communications and communities are created as conduits of emotional dialogues through communication services. Besides, Online brand suggest new culture as they conduct groundbreaking and magnetic services, which are related to four pillars or have broader concept through integrating the characteristics of four pillars.

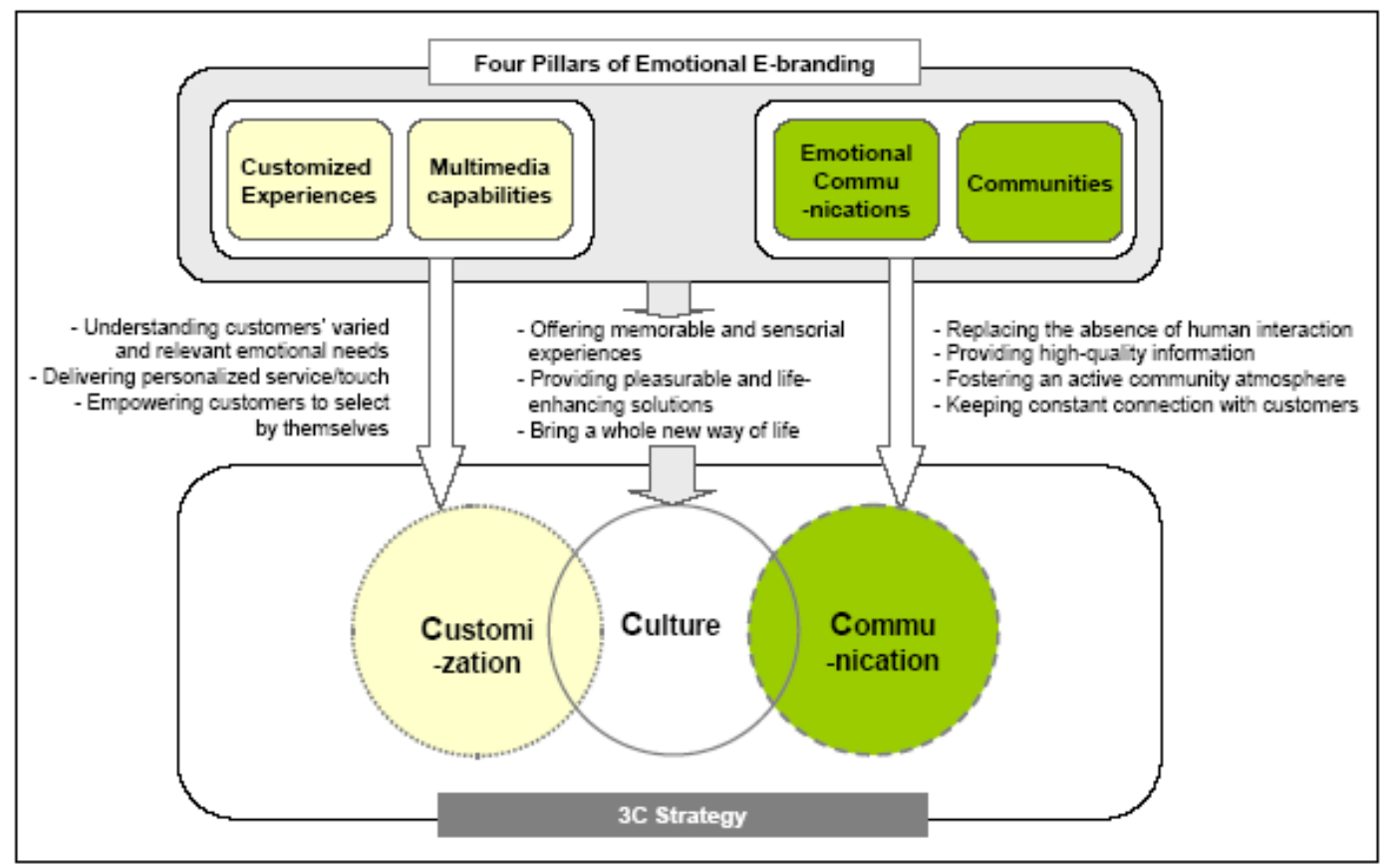

Fig. 4 A process of developing a " $3 \mathrm{C}$ strategy" from four pillars of emotional e-branding

Among the three elements of $3 \mathrm{C}$ strategies, firstly, customization refers personalized experiences geared to individual tastes and preferences, which are revealed by continuous dialogues with customers. Also, customization empowers consumers to design and purchase the products for themselves, according to their tastes and needs [8]. Furthermore, recent state of the art technology allows for diverse customization services that were considered impossible before. For example, a website of Lands' End has virtual models customized to the consumer's measurements and body type, and these models can be easily dressed with different outfits [1]. This custom-fitted 
clothing service offers customers a chance to see how clothes will look on them before they buy with the simple click of a mouse. Secondly, communication plays an imperative role in the online environment in terms of replacing the absence of human interaction; furthermore, communication has the potential for fostering an active and warmhearted community atmosphere where people have the opportunity to engage in a dialogue with one another. Through community activities, customers recommend products or share their favorite brand with others. Finally, through a new service related to customization, communication, and so on, novel cultures are created and occasionally traditional cultures are vanished. Online brand enhance a customer's lifestyle by providing pleasure and life-enhancing solutions and offering memorable and sensorial experiences. By integrating these three elements, the Customisation, Culture and Communities Strategy creates e-brand awareness and unique brand identity through providing enthralling sensorial experiences, forms symbiotic partnerships through interactive dialogues, and then creates rapport with customers through an emotional bond on the web.

\section{Research Methods}

This research has conducted in three stages. Firstly, from the literature review, we conduct research on emotional branding with an emphasis on sensorial experiences and emotional dialogues with customers and also investigate the characteristics of Online brand. Secondly, an emotional branding approach to Online branding is suggested as a way to heighten online shopping experiences in a hyper-competitive online marketplace. The essential characteristics of emotional e-branding, four pillars-emotional communications, customized experiences, multimedia capabilities, and communities-, are suggested. As an emotional e-branding method for integrating and embodying these four pillars, a "Customisation, Culture and Communities Strategy" is developed. Finally, in order to identify the possibility of applying the Customisation, Culture and Communities Strategy to the development of vibrant online brands, we conduct a case study with the well-established Online brand selected in terms of the Customisation, Culture and Communities Strategy, and analyze their experiential and emotional aspects. From the results of e-brand analysis, the effects of emotional brand contents and the designer's role of illustrating and visualizing ebranding concepts are considered. The following Fig.1 explains the overall research contents and methods.

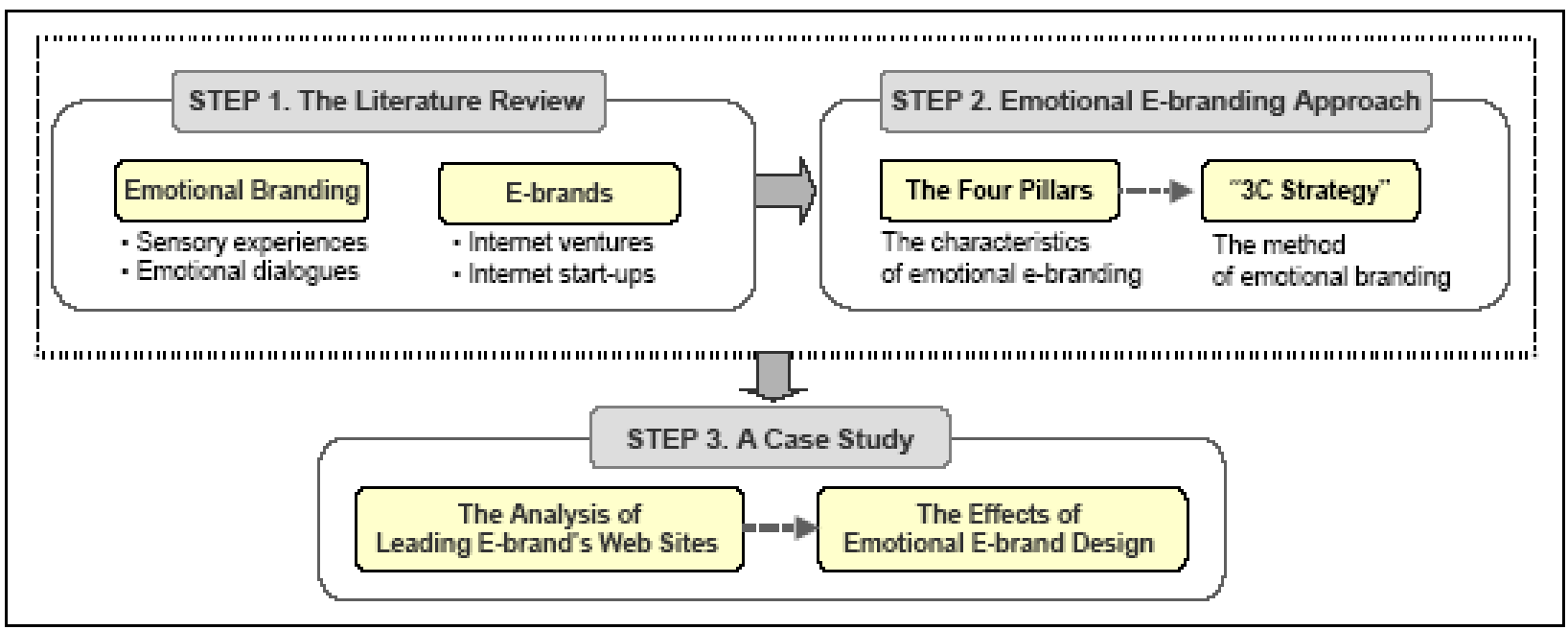




\section{A Case Study for Identifying the Effects of Emotional E-brand Design}

\subsection{Selecting Online brand with Customisation, Culture and Communities Strategy.}

Based on Customisation, Culture and Communities Strategy, the experiential and emotional aspects of cutting-edge Online brand in industries are analyzed as a case study. We selected six well-established ebrand websites: Alibaba.com, Lazada.com, Bukalapak.com, Ebay.com, Amazon.com, and Mataharimall.com. The reason for selecting these sites is their particular services and their frequent citations of ecommerce books [2], [9], [10], [11]. Six Online brand can be categorized as illustrated in Fig. 6 according to each site's unique service: (1) Alibaba.com and Lazada.com provide delicate personalized customization services; (2) Bukalapak.com and eBay.com establish electric communication service areas; (3) Amazon.com and Mataharimall.com suggest new lifestyle in the realm of culture. In particular, Amazon.com and Mataharimall.com, which create attractive digital culture, build up a different atmosphere from the physical world by providing services of customization and communication, which make customers gather according to their interests. Surprisingly, members of Mataharimall.com create their own distinctive words and share these words between other members, and some members severely participate in this site and excessively involve in community activities, a so called "fashion addiction." The following Table 1 explains the selected six Online brand' well-organized services, categorized into Customisation, Culture and Communities Strategy.

These services form the chief characteristics and contribute to the popularity of each site. Most importantly, the correspondence of these services with the three elements of the Customisation, Culture and Communities Strategy implies that the services associated with the Customisation, Culture and Communities Strategy based on customer's sensorial experiences play an important role in the ebrand's success as the mainspring of ebranding, adding emotional elements to the e-brand.

Most importantly, the correspondence of these services with the three elements of the Customisation, Culture and Communities Strategy implies that the services associated with the Customisation, Culture and Communities Strategy based on customer's sensorial experiences play an important role in the e-brand's success as the mainspring of e-branding, adding emotional elements to the e-brand.. 
Table 1. Analysis of Six Online Brands

\begin{tabular}{|c|c|c|c|}
\hline \multicolumn{2}{|c|}{ E-brand } & \multirow{2}{*}{$\begin{array}{c}\text { Customisation, } \\
\text { Culture and } \\
\text { Communities } \\
\text { Strategy } \\
\text { Customization }\end{array}$} & \multirow{2}{*}{$\begin{array}{l}\quad \text { Unique Service } \\
\text { A custom beauty service that meet } \\
\text { customer's specific beauty needs and } \\
\text { desires through individualized } \\
\text { attention. }\end{array}$} \\
\hline Alibaba.com & $\begin{array}{l}\text { The world's } \\
\text { Interactive online } \\
\text { groceries company }\end{array}$ & & \\
\hline Lazada.com & $\begin{array}{l}\text { An online store } \\
\text { service company }\end{array}$ & Customization & $\begin{array}{l}\text { 1. Online albums that keep the } \\
\text { uploaded pictures from customer's } \\
\text { digital camera and enhance pictures } \\
\text { by easily using various picture } \\
\text { managing services. } \\
\text { 2. A web-based photo service with } \\
\text { which customers manage, enhance, } \\
\text { share, and print pictures at once }\end{array}$ \\
\hline Amazon.com & $\begin{array}{l}\text { The supreme } \\
\text { online book store }\end{array}$ & Culture & $\begin{array}{l}\text { 1. [Customization]: A registered user's } \\
\text { individual store, which includes } \\
\text { personalized recommendations and } \\
\text { wish lists about favorite and new } \\
\text { books. } \\
\text { 2. [Communication]: A review service } \\
\text { that provides and shares opinions of } \\
\text { editors and other customers about } \\
\text { books. }\end{array}$ \\
\hline Mataharimall.com & $\begin{array}{l}\text { An online fashion } \\
\text { store } \\
\text { company }\end{array}$ & Culture & $\begin{array}{l}\text { 1. [Customization]: Communities for } \\
\text { digital camera mania according to } \\
\text { interests. } \\
\text { 2. [Communication]: Complete and } \\
\text { valuable information about digital } \\
\text { cameras from purchase to usage. }\end{array}$ \\
\hline Bukalapak.com & $\begin{array}{l}\text { An in-depth } \\
\text { information site of } \\
\text { news, reviews } \\
\text { about digital } \\
\text { cameras }\end{array}$ & Communication & $\begin{array}{l}\text { A comprehensive database of digital } \\
\text { camera features and specifications, } \\
\text { digital camera reviews, current } \\
\text { digital photography news, and } \\
\text { discussion \& article forums }\end{array}$ \\
\hline Ebay.com & $\begin{array}{l}\text { The world's online } \\
\text { marketplace }\end{array}$ & Communication & $\begin{array}{l}\text { A global trading platform where } \\
\text { diverse communities of individuals } \\
\text { and businesses can trade practically } \\
\text { anything with dedication to its } \\
\text { community members. }\end{array}$ \\
\hline
\end{tabular}




\subsection{Results of E-brand Content Design Analysis.}

Emotional experiences through customisation online (e-branding) strategy are ultimately presented in the online context where contents are included. In addition, contents eventually embody emotional elements by inserting "humantouch" into "techno-boring" sites. To actualize emotional e-branding strategies, the content, a container holding emotional elements, is imperative to be visualized in more sensitive ways. Consequently, a designer's role in expressing emotional experiences in the web contents creation also has to transcend simple aesthetic visualization and then offer the pleasant experiences by innovatively designing the ebrand's features such as easy navigation, cozy communication environments, eyecatching high-quality information, impressive memorable services, and so on. On the verge of a market inundated with newly empowered customers, designers create contents not only meeting customer's taste, but also satisfying the active customers with self-selecting services. For example, Mataharimall's custom fashion service, designed in a whole new way, allows women to concept, design, name, and label their own individual cosmetic lines. The custom beauty processes are: (1) to inquire about taste and lifestyle; (2) to explore categories of items; and then (3) to proceed to design personalized products and packaging [2]. Some questions in this process are composed of multi-sensorial images presenting visual, odorous, and nutritious attributes of cosmetics.

With these self-selecting services, another important design method is to create an emotionally charged environment providing unforgettable experiences through multi-sensorial media, and then to give customers various ways to interact with the e-brand's contents in this environment. For example, Bukalapak.com provides high quality information on the latest digital cameras with well-organized visual elements used in a variety of ways: "Timeline" menu shows the recent trends of digital cameras chronologically; "Gallery" displays pictures taken by each digital camera; and "List" presents a database of approved affiliates, linking related online shopping malls directly. Through these three methods, dpreview.com is emotionally interacting with its customers by satisfying their varied and relevant digital camera needs. Also, Alibaba.com's sensorial interface elements build an attractive service environment, and its various personalized picture-managing services create continuous rapport with customers by giving new experiences coinciding with their desires.

The emotional contents design of Lazada.com enhancing customization service custom Eye shadow made by the customer: selecting colors and creating a name, Choosing a nutrient infusion, through pictures showing ingredient Selecting accent color of packaging Choosing favorite sent through pictures of sent images. Sensorial interface design and personalized services of 
Alibaba.com The picture-managing services for enhancing pictures: fix, crop, effects, and borders The online albums that keep and share pictures quality information on the latest digital cameras with well-organized visual elements used in a variety of ways: "Timeline" menu shows the recent trends of digital cameras chronologically; "Gallery" displays pictures taken by each digital camera; and "List" presents a database of approved affiliates, linking related online shopping malls directly. Through these three methods, dpreview.com is emotionally interacting with its customers by satisfying their varied and relevant digital camera needs. Also, Alibababa.com's sensorial interface elements build an attractive service environment, and its various personalized picture-managing services create continuous rapport with customers by giving new experiences coinciding with their desires. After all, designers have to visualize ebrand's sensorial experiences focusing on the entertainment value, connectivity, and memorability of the contents.

\section{Conclusions}

Building an enduring, leading ebrand has never been a simple task, but profound emotional rapport with consumers through emotional dialogues makes this job less burdensome and considerably more profitable in the long run. Therefore, brand managers and designers have to learn the nuances of serving newly empowered consumers and to realize the significance of more satisfying and rewarding e-branding in order to touch customers emotionally. Thus, based on understanding electric consumer's behavior and emotional relationship with the consumer, this study investigates the possibility of applying an emotional branding approach to creating and marketing an e-brand in order to captivate its customers' attention and increase the ebrand's competitiveness. This study focuses on the way of building emotional branding, which has the potential to fulfill customers' desires and enhances the e-brand's value. Through the research, the Customisation, Culture and Communities Strategy is recommended as an e-branding method, and the possibilities and effectiveness of applying this method to Online brand are identified through a case study. This study emphasizes the value of the e-brand's sensorial experiences based on elements of customization, communication, and culture as well as the designer's new role of building an emotionally charged virtual environment for visualizing an e-brand's emotional concepts in multi-sensory ways. Furthermore, with more attention to development of diverse strategies for effective e-branding, the new role of design that visualize meaningful and valuable brand touch points in cyberspace also needs to be thoroughly investigated. 


\section{References}

1. Marc Gobé, Emotional Branding, Allworth Press, New York, p. xiii-xxxiii, p. 244-245, p. 264, 2001.

2. Jerry Kathman, "Brand Identity Development in the New Economy", Design Issues, vol. 18, no. 1, pp. 24-35, Winter 2002.

3. Phil Carpenter, eBrands: building an internet business at breakneck speed, Harvard Business School Press, Boston, Massachusetts, pp. 2-3, 2000.

4. Bernd Schmitt, Experiential Marketing, The Free Press, New York, pp. 11-32, pp.72-95, 1999.

5. Daryl Travis, Emotional Branding: how successful brands gain the irrational edge, Prima Publishing, California, p. 3, 2000.

6. Arthur Cheng-Hsui Chen, "Using free association to examine the characteristics of brands associations and brand equity", Journal of Product \& Brand Management, vol. 10, no. 7, pp. 439, 2001.

7. Bernd Schmitt, "Creating and Managing Brand Experiences on the Internet", Design Management Journal, pp. 53, Fall 2000.

8. Mai-lan Tomsen, Killer Content: Strategies for Web Content and E-Commerce, Addison Welsleys Longman, Inc., pp. 108-111, 2000.

9. Bernt H. Schmitt, Customer Experience Management, John Wiley \& Sons, Inc., pp. 170-172, 2003.

10. Perter S. Cohan, e-profit: High Payoff Strategies for Capturing the E-Commerce Edge, American Management Association, pp. 201-205, 2000.

11. Lynn B. Upshaw, Building a brand.comm, Design Management Journal, pp. 37, Winter 2001. 